and lard, $3 j^{*} ;$ to be applied to both eyes; and castor wil, 3 ss; to be taken directly. 23rd: The discharge very much lessened, the cornea cannot be seen distinct$1 y$; but appears clear; the syringing and ointment to be repeated. 24th. Discharge decreasing. Cont. remed. 25th. Discharge has not appeared since yesterday; the eyes are quite open, and the cornea quite clear from nebula or ulceration. Nitrate of silver lotion in the proportion of ten grains to the ounce of water, to be dropped into the eyes. 26 th. Discharged quite cured.

John W., set. 22, has had gonorrhoea for the last three months, for which he has received medical treatment; on the $16 \mathrm{th}$ of October he was attacked by inflammation of the left eye; he is not aware of having applied the discharge from the urethra to the eye; on the 20 th I first saw him, the conjunctivæ much inflamed and chemosed, of a pale red colour, discharging a large quantity of puralent matter; the cheek nuch excoriated from the discharge; the eye was well washed with warm water, and the black ointment applied. An emetic of mag. sulph., ₹ss.; ant. tartratis, gr. ij.; to be taken at bed-time. 21st. Eye much improved, discharge less, can bear a little light; the same treatment was continued daily until the $26 \mathrm{th}$, when he was quite well.

My desire to bring the above cases forward is not with the object of recommending a new remedy, for I may almost say the certain cure of a disease which, if allowed to run its course even for a few hours in some cases, will terminate in the total destruction of the eye; but with a wish to make a treatment which was brought forward many years ago by Mr. Guthrie more generally known. Surgeons have objected to the use of the black ointment in purulent or gonorrhoeal ophthalmia for two reasons : one, because it produces pain when applied to the inflamed conjunctiva; the other, that they see no use in using a violent remedy when the disease may be checked by milder ones, and at the same time stating that they can wait a few days, and should the alum lotion and other such mild applications fail, they may have recourse to the severe. Now, these are two most absurd objections for trifling with the future happiness of any individual. In the first place, is it not better to put a stop to disease ut once with a little pain, than allow it to linger on and terminate no one knows how? They might as well say that pain should not be produced by the knife ii a case of strangulated hernia in which the pain has ceased from mortification. As for the second objection; they will not use ointment until the disease has existed sume time. Now, every one knows, who has seen much ophthalmic practice, that purulent matter when allowed to remain in contact with the cornea, even a few hours, will produce the most scvere disasters, sloughing, not only of the cornea, but the whole strur. ture of the organ; it is not supposed that any remedy will cure the disease at this crisis, but the remedy should be applied in time to prevent those dreadful terminations. I re. member some time since a surgeon in the country, after using lotions and blowing calomel into an eye affected with this disease for days ineffectually, stated that he was afraid to use Mr. Guthrie's ointment, because it produced such pain. If purulent ophthalmia be properly taken care of from the very commencement, and the eyes syringed with mild stimulants every quarter of an hour, I have no doubt but that the disease will be subdued; but how seldom do we find that the class of patients whose children are afflicted, will take due care? If they make an attempt, how few mothers, particularly of the lower orders, will open the child's palpebra and remove every particle of the poison? I have repeat. edly stood by, and desired them to cleanse the infant's eye, when they bave applied the remedy externally instead of internally. Of course the nitrate of silver ointment, like all other remedies, must occaisionally fail, but I may safely say that nineteen of every twenty, will recover without nebula or any obstruction to vision. Before the ointment is applied the conjunctiva should be well cleansed with warm water, when about the size (not as Mr. Houston in his edition of Mr. Little's work, page 51, states, the size of a pin's head) of a split pea of the unguent is to be applied with a camel's-hair brush, having been previously softened before the fame of a lamp, to the conjunctiva, when friction is to be used externally to the lids, so as to diffuse it over the whole internal sur. face; having been allowed to remain five or ten minutes it is to be removed with warm water; should there be much inflamimation and swelling of the lids a leech may be applied to the external angle of the eye. I have given the above directions, festring that a great number of the cases in which the application has failed is in consequence of its improper application.

\section{GANGRENOUS ULCERATION OF THE INTEGUMENTS.}

\section{Conduct of a "Pure" to a General PRACTITIONER.}

\section{To the Editor of THE La NCET.}

Sir:-Your inserting the following case in the forthcoming Number of your valuable Journal will much oblige, Sir, your obedient servant,

2, Great Marlborough.street. Jan. 16, 1830. 
On the 19th Dec: last, I was requested to gttend Mrs. D., who was delivered of a fine healthy-looking child; both went on extremely well, to all appearances, until the 2nd of January, when the nurse, for the first time, called my attention to two rather extensive sloughs between the shoulders of the infant, a little larger than a crown each, very much resembling burns, or eschars from some caustic application, with very considerable inflammation around them; the cliild slept and took the breast extremely well. I prescribed a powder containing mercury and chalk, one grain; rhabarb, two grains, thrice a day, to act on the bowels, and orfered the application of a liniment, composed of chalk and olive oil, to the sores, and the inflamed surface around them to be bathed with Goulard water.

Jan. 3. Inflammation around the sloughs decreasing; sores much the same; bowels free; stools more healthy in appearance.

4. Inflammation subsiding; sores ceased to spread; and the child continnes to suck and sleep well, never crying but when the sores are dressed.

6. The child's constitution does not seem to suffer; the inflammation round the sores nearly gone; rests and sucks freely. Persist in the use of the. Intion and liniment.

8 and 9. Process of absorption beginning around the sloughs.

10. Sores seem much the same as yesterday. The child has been out yesterday and slept almost all night afterwards, and takes the breast freely.

11. The mother took the child to Dr. Roe of Hanover-square, who, on seeing it (she says) exclaimed, it was the most cruel case he had evor seen; inquired who bad been in attendance, and was informed that $I$ had. He then inquired who I was. She replied, "Mr. Russell's partner." "W What, the gentleman who attended you in rheumatic fever ?" "Yes," was the reply. "Well (said Dr. Roe), the child has been very improperly treated; what has been done has been very injurions, and no doubt has been the means of bringing it into this state. You must go home, take no notice of your medical attendant, apply a pouitice to the sores, give the following medicine, and $I$ will cure it for you :-

"Iodine, 1 grain;

Hydriod. of potass, 1 drachm ;

Distilled water, 2 ounces. One drachm thrice a day.

Mercury and chalk, 2 grains ;

Rlubbarb, 2 grains. To be taken at night."

On Saturday morning my partner, $\mathrm{Mr}$. Russell, called to see the child, as I was ill in bed, and, somewhat to his astonishment, found it had died at two o'clock that morning, and that the family was much exasperated against me, (fully believing what Dr. Roe No. 804. told the mother); I therefore insisted on a post-mortem examination, which was made on Monday morning, in the presence of several eminent members of the profession; but I am sorry to say it did not throw any light on the subject, as there was no inflanmation in the stomach or bowels, nor anything to account for death so suddenly, except that, on testing the contents of the stomach, traces of iodine were found. Pre. vious to the examination of the body, we sent for the mother of the child, who gave the following account of it:-About an hour before slie took it to Dr. Roe, it took upwards of a wineglassful of milk, and did not seem changed in any other respect; at 11 A.N. she gave it the first dose of the mixture, which produced almost immediate vomiting, followed by short and panting respiration, cold clammy perspiration, eyes sunk in the head, and, to use the words of its parents, was quite an altered child ever afterwards, refusing the breast and everything that was offered; but they thought that, perhaps, the medicine was working a wonderfulcuref; ergo, gave a second dose at 5 P.M., and $\mathfrak{a}$ third at $\frac{1}{2}$ past 2 in the morning. It continued in that cold state until nine in the morning, when romiting came on, followed immediately by death.

Now, Sir, it is not my intention to enter into a discussion as to the quantity of hydriod. of potass an infant three weeks old would bear; for, in the first place, I should not have ordered it at all under these circumstances, at that early age, and if $I$ had, I certainly should not have ordered onetwelfth of the dose this infant took in one day, namely, nearly 12 grains of hydriod. of potass and one-sixth of a grain of jodine, Had I deemed it expedient to call an inquest on this child, I think it would have been a question for the serious consideration of the jury, whether the above dose was a proper one to be prescribed for an infant of three weeks; but of this question, and what the verdict of a jury would probably hare been, I will leave the profession to judge. It appears that about three years ago, Mrs. D. went to consult Dr. Roe, accompanied by her mother, when she was recovering from an attack of acute rheumatism; she declares that he said she had been very improperly treated by my partner, Mr. Russell, which assertion left a very unfavourable impression on her mind, and, in fact, was the cause of her going to Dr. Roe on this occasion.

I am utterly ignorant of any cause which Dr. Roe can have had for attacking the cha: racter of either $\mathbf{M r}$. Russell or myself, - I will make no comments, or express any opivion on his conduct, beyond inquiring of ny professional brethren, whether it +is'justifiable on the part of a Fellow of the College of Physicians to make such an attack on a general practitioner who has been previously in attendance, without even knowing $2 \mathrm{U}$ 
the history of the case or what treatment had been adopted.

** If Dr. Roe have acted in the way represented by $\mathrm{Mr}$. Wadsworth, his conduct was highly reprehensible. A little union amongst general practitioners would, however, soon bring persons who act in the manner described by our correspondent, to their senses. Let them never be called in by the general practitioner, and self-interest will quickly compel them to abandon a line of conduct which is equally unworthy of honest men and members of a liberal profes. sion.-FD. L.

\section{THERAPEUTIC QUALITIES OF PRUSSIC ACID.}

\section{To the Editor of The Lancet.}

SIR:-The lamented death of Mrs. Maclean has called the attention of the public to the merits of hydrocyanic acid as a therapeutical agent, and many have already imbibed the idea that prussic acid is a most dangerous poison, and perfectly useless in the treatment of disease. The Times copied yesterday a long paragraph from the Edinburgh Courant, in which the writer observes, "It ought to be generally known that there are no diseases capable of being alleviated by prussic acid which may not be, with equal certainty, relieved by other and safer means. The patient, therefore, who uses it at his own risk, runs the most imminent hazard of his life; and the physician who prescribes it, without the most cogent necessity, does little less than sport with the life of his patient. The writer of these remarks has been twentytwo years in practice, during which pe. riod he has seen many thousand cases of all descriptions, and in all classes of society, and yet he has never once had occasion to prescribe prussic acid, having always accomplished the end he had in view by other means. He knows active practitioners, of still longer standing, who can make a similar statement; but he is sorry to add that he knows much YOUNGER MEN who employ it often and with much too little caution."

Now, Sir, the writer makes a grave charge against the members of our profession. Happy man! he has treated " many thousand cases of all descriptions, and has always accomplished the end he had in view." Others, however, have not exercised the same skill, do not possess exactly the same chest of simples, and, therefore, with " tou little caution," make use, frequently, of this valuable medicine; and I, for one, shall continue to use it, even at the risk of being accused of "sporting with the lives of my patients." Without being able to boast of "twenty-two years experience," I may be allowed to mention the case of a young lady, who had for several days been unable to re. tain a particle of food upon her stomach; even fluids were immediately rejected; every means had been used by the medical gentleman who attended her, bat in vain, and at his urgent request a physician was sent for. What was the remedy? R. Hy. drocy. acid, two minims (Scheele's); orange syrup, thirty minims; water, one ounce; a draught every fourth or sixth hour; and I had the happiness of seeing my friend restored to health, the sickness ceasing after the exhibition of the second draught. Nor is this a solitary case; only last week I saw it given in a similar case, though not so violent, with the best effect.

It has, however, justly been remarked, that some test ought to be employed to ascertain the strength of the acid employed. In the last edition of the "Pharmacopoia Londinensis" we have the acidum hydrocyanicum dilutum, which differs in strength from the preparation commonly used under the name of "Scheele"s," and, therefore, in a remedy so important, as well as so powerful, an uniformity of strength ought to be preserved. Hydrocyanic acid consists of, 1 Nitrogen $=1$ by $14=14$

2 Carbon.. $=2$ by $6=12$

3 Hydrogen $=1$ by $1=1$

27

The strength of any solution of this acid may, according to Dr. Ure, be ascertained by adding to 100 grains of the hydrocyanic acid small quantities of the peroxide of mercury, in fine powder, until it ceases to be dis. solved. The weight of the peroxide dis. solved, divided by four, gives the quantity of real acid present. The rationale is this: the equivalent of peroxide of mercury, 216, happens to be just eight times that of prussic acid, 27; therefore, as the prussiate of mercury consists of two proportions of prussic acid to one of base, it is evident that the quantities of acid and of base in the salt are in the ratio of one to four.

Let us now examine the componnds of this acid.-Laurel-water : this is the distilled water of the leaves of a species of cherry, the prunus laurocerasis of Linnæus, a native of the coast of the Black Sea, although it is now very common in Europe, into which it was brought about the end of the six. teenth century. It belongs to the natural order, amygdalace. The volatile oil residing in the leaves and kernels of the fruit is combined with hydrocyanic acid. The flowers, as well as the leaves, have the odour and taste of the bitter almond and the kernel of the peach, and communicate both, readily, to boiling milk, cream, diluted alcohol, and other substances, in which form they are used as condiments-very improperly, and by ignorant servants.

Oil of bitter almonds.-The seed yielding the greatest quantity of combined hydrocy. 